\title{
Achieving the IASB's Output Legitimacy: A Prescriptive Model
}

Jenice Prather-Kinsey - PratherKinsey@uab.edu

Francesco De Luca - francesco.deluca@unich.it

Ho-Tan-Phat Phan-hotanphat.phan@unich.it

\section{Motivation and Objective}

The objective of this study is to develop a framework to achieve output legitimacy for the IASB.

The IASB lacks output legitimacy or global rigorous enforcement of compliance with IFRS as published by the IASB. This negatively affect comparability of accounting information across countries and for cross listing companies

\section{Practical implications}

Provide a more comparable accounting information worldwide in the investors' perspective

\section{Methodology}

We apply normative modeling to prescribe a

framework for IASB's output legitimacy of its IFRS. $\rightarrow$ Qualitative Analysis through NVivo of documents from IASB and IOSCO:

- Content analysis of all documents from IASB's website (2006-2019).

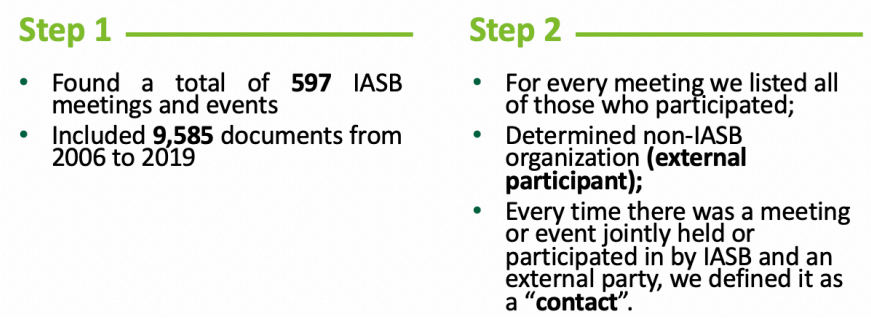

- Content analysis of all documents from IOSCO's.

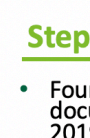

Step 1
Found
docum
2019

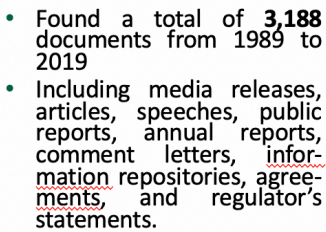
Step 2 - Used NVivo to shortlist

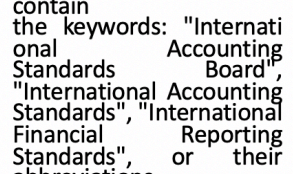

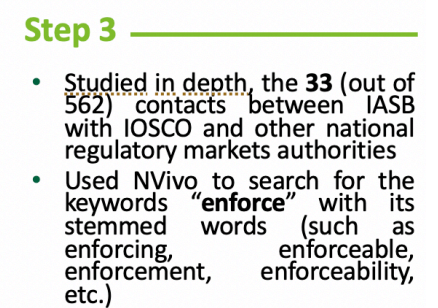
enforer

Step 3

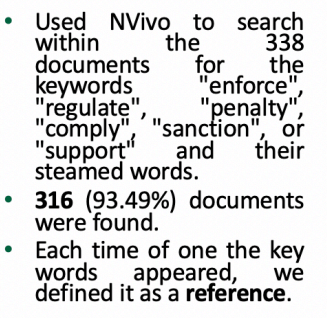

Step 4

- Matched the $105 \mathrm{sco}$ time fame $(2006$ to
$2019)$

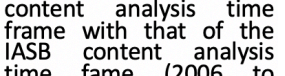
Resulting in $239105 \mathrm{OSCO}$
documents and 17,132
keyword references.

\section{Findings}

Most of the references regarding enforcement activities are mentioned in meetings that are not participated by authority parties. They appeared in the meeting of IFRIC, or IASB itself, or joint IASB and FASB meetings.

Generally, IASB had most of its contacts (24.56\%) with national standard setters. More than half of these contacts are from the joint meetings between the IASB and FASB (76 out of 138 observations). However, we found only $2.14 \%$ (12 meetings) of the total contacts with IOSCO and $3.74 \%$ (21 meetings) with national financial market authorities. This paucity of meetings between IASB and national market authority parties could suggest that IASB should meet more often with IOSCO and national market authorities in pursing enforcement of IFRS to achieve output legitimacy.

We conclude that enforceable standard is a goal of IASB but it has not been achieved yet.

\section{Conclusions}

Firstly, we propose IOSCO as a central portal and enforcement of IFRS as published by the IASB. Secondly, we support the comment letter approach to review a cross-listed firm's financial reporting filings under IOSCO's authority.

Thirdly, a final IFRS compliance or non-compliance ruling would be made by and disclosed by IOSCO along with all comment letters. 